\title{
AUTOBIOGRAFIA LINGUÍSTICA. ATITUDES, CRENÇAS E REFLEXÕES PARA O ENSINO DE LÍNGUAS
}

\author{
AUTOBIOGRAFÍA LINGÜÍSTICA. ACTITUDES, CREENCIAS Y REFLEXIONES \\ PARA LA ENSEÑANZA DE IDIOMAS
}

\section{LINGUISTICS AUTOBIOGRAPHY. ATTITUDES, BELIEFS AND REFLECTIONS FOR LANGUAGE TEACHING}

Irania MALAVER ${ }^{1}$

RESUMO: Este artigo se realiza a partir de uma pesquisa qualitativa baseada na autobiografia linguística como recurso para a análise sociolinguística de crenças, percepções e atitudes linguísticas e, além disso, como método de autorreflexão para o professor de segunda língua, com o qual ele pode aprofundar o desenvolvimento de sua própria competência cultural e dos aprendizes. A autobiografia linguística de uma professora multilíngue é analisada, suas vivências em torno dos idiomas que marcaram sua vida, sua família e ambiente de trabalho: não apenas quais idiomas ela fala, mas o que sente sobre eles e sobre a comunidade que os emprega. Além da autobiografia, uma entrevista aberta e um retrato linguístico são realizados como ferramentas para se aproximar da proposta subjetiva e individual da construção da identidade linguística.

PALAVRAS-CHAVE: Autobiografia linguística. Atitudes e crenças sociolinguísticas. Retrato linguístico.

RESUMEN: El presente trabajo es una investigación de corte cualitativo basada en la autobiografía lingüística como recurso de análisis sociolingüístico sobre creencias, percepciones y actitudes lingüísticas y como metodología de autorreflexión para el docente de segundas lenguas, con el que puede profundizar en el desarrollo la competencia cultural propia y de los aprendices. Se analiza la autobiografía lingüística de una docente plurilingüe, sus experiencias alrededor de las lenguas que han marcado su vida, su entorno familiar y laboral: no solo qué lenguas habla, sino qué siente sobre ellas y sobre la comunidad que las emplea. Además de la autobiografía, se realiza una entrevista abierta y un retrato lingüístico como herramientas de acercamiento al planteamiento subjetivo, individual, de construcción de la identidad lingüística.

PALABRAS CLAVE: Autobiografía lingüística. Actitudes y creencias sociolingüística. Retrato lingüístico.

ABSTRACT: This work is a qualitative cutting research based on linguistic autobiography as a resource for sociolinguistic analysis on linguistic beliefs, perceptions and attitudes and

${ }^{1}$ Universidad Central de Venezuela (UCV), Caracas - Venezuela. Profesora Titular. Doctorado en Lingüística Aplicada de la Universidad de Alcalá. ORCID: https://orcid.org/0000-0002-7773-0234. Correo: imalaver@hotmail.com 
as a methodology of selfreflection for the teacher of second languages, with which development of one's own cultural competence and apprentices can deepen. It analyses the linguistic autobiography of a multilingual teacher, her life around the languages that have marked her life, her family and work environment: not only what languages she speaks, but how she feels about them and the community that employs them. In addition to the autobiography, an open interview and a linguistic portrait are conducted as tools of approach to the subjective, individual approach to the construction of linguistic identity.

KEYWORDS: Linguistic autobiography. Sociolinguistic attitudes and beliefs. Linguistic portrait.

\section{Introdução}

"Como aprenderam as línguas que falam? Que tipo de alunos terão?” Onde ensinarão espanhol? O que conhecemos de nossos alunos?" Costumo fazer essas perguntas aos meus alunos, futuros professores ELE, a fim de conhecer suas expectativas e motivações, além de problematizá-los sobre as arestas sociolinguísticas em que se desenha o ensino de segundas línguas. Aprender espanhol como língua materna e língua estrangeira é refratado em múltiplas superfícies, tanto didáticas quanto sociais. Para este caleidoscópio sociolinguístico, o professor deve se preparar e sensibilizar perante falantes diversos - universitários, profissionais, refugiados, estudantes lúdicos, multilíngues ou bilíngues - e desenvolver metodologias de ensino-aprendizagem que reconheçam as experiências vitais significadas pela língua, que são urgentemente necessárias para falar, a eu se deseja aprender, como mostram os depoimentos de Okba Aziza (1), un refugiado sírio e Nengumbi Sukama (2), refugiado congolês: ${ }^{2}$

(1) Nasci na Síria e agora me mudei para a Argentina vindo com o Programa Síria para recomeçar minha vida aqui.. Como todos sabem, temos uma situação horrível e difícil lá na Síria. É por isso que estou aqui agora em Buenos Aires. Minha história com a Argentina começa quando eu era um garotinho. Vi um desenho chamado "Adios Marco" na Síria e a história diz que Marco é um menino italiano que veio para a Argentina em busca de sua mãe, que estava trabalhando aqui para sustentar sua família. E também como eu gosto de história e geografia eu tinha lido muito sobre a América Latina por meio da nossa escola ou em livros e leituras.

(2) Desde agosto de 1995 moro aqui na Argentina. O idioma era minha primeira necessidade. Como profissional, entendi que, para estruturar uma nova vida em uma nova sociedade, o idioma era a principal ferramenta. $\mathrm{Na}$ semana seguintena formalização do pedido de asilo, iniciei os cursos. E, então, quatro meses depois pude entender a semelhança entre francês $e$

2 Tradução do inglês extraído de Línguas para Resiliência: ensino de línguas para refugiados e migrantes. Conselho Britânico. Disponível em: https://argentina.britishcouncil.org/sites/default/files/programa_lenguas_para_la_resiliencia_spanish.pdf. Acesso em: jan. 2020. 
espanhol. Felizmente para mim, domino muito bem o francês que é quase semelhante ao espanhol. Custou-me os primeiros quatro meses, depois não foi tão difícil. Mas como foi uma obsessão dominar espanhol em pouco tempo.

Este artigo trata da autobiografia linguística; trata-se de uma pesquisa qualitativa na qual, a partir de um estudo de caso, estudamos o discurso narrativo autobiográfico das avaliações em relação a línguas, atitudes e crenças: o que o falante sabe sobre sua língua, as línguas que conhece, o que sabe sobre seu contexto comunicativo, a realidade sociolinguística que o cerca e como a língua sustenta ou não a construção de sua identidade. Trata-se, nesse sentido, de um trabalho da perspectiva da ampla sociolinguística, especialmente da sociolinguística cognitiva (cf. MORENO FERNANDEZ, 2012). Por outro lado, na perspectiva do ensino de segundas línguas, este trabalho apresenta a autobiografia linguística como estratégia com a qual o professor pode aprofundar sua competência intercultural, bem como a de seus alunos, aprimorando estratégias de ensino que reconheçam as experiências emocionais na aprendizagem de uma segunda língua (CONSEJO DE EUROPA, 2001).

Além dessa introdução, o artigo é organizado em diferentes seções. A primeira seção é dedicada à definição de biografia linguística no contexto da pesquisa sociológica e sociolinguística e cita algumas pesquisas que servem de base conceitual-metodológica para nossos propósitos; a segunda seção contém o desenho da pesquisa; e na terceira seção apresentamos a história e sua análise. Finalmente, aparecem as considerações finais.

\section{A biografia linguística}

Biografias linguísticas são relatos autobiográficos em que as línguas são o centro narrativo: memórias familiares, experiências escolares, trabalho e profissão, lugar onde você vive, viaja, ou seja, tudo o que é conta e se comenta sobre, a partir do eu biográfico, em uma narrativa que mantém uma relação próxima com a língua e os processos de socialização e identidade. Como metodologia (BOLÍVAR; PORTA, 2010; PUJADAS, 1992) e faz parte de toda a história de vida: narrativas de experiências pessoais com as quais fenômenos sociais coletivos podem ser analisados a partir da ação individual (cf. MOLINI, 2006). No nosso caso, estamos interessados, desde o olhar e a voz do eu protagonista, as vivências, as experiências e práticas linguísticas que geram e explicam atitudes, julgamentos, sentimentos e valores em relação à língua: "Além das teorias subjetivas do falante sobre aquisição de língua e uso adequado da língua em diferentes circunstâncias sociais e comunicativas, a abordagem linguístico-biográfica também aborda construções relacionadas à identidade linguística 
individual e coletiva.”3 (2004 apud NOVAK, 2012, p. 400). A biografia linguística é uma ponte tecida com vivências e experiências filtradas pelos significados simbólicos das línguas. Começamos a partir da definição proposta por Nekvapil (2003), em seu estudo sobre a comunidade alemã da antiga Checoslovaquia:

Por uma biografia linguística eu entendo um relato biográfico no qual o narrador faz de uma língua, ou de línguas - e sua aquisição e uso em particular - o tema de sua narrativa (cf. FRANCESCHINI, 2001a; 2001b). No entanto, uma língua não é meramente uma questão pessoal: o indivíduo aprende com alguém e a usa com alguém (dentro e fora da família), e é por isso que as autobiografias linguísticas incluem naturalmente aspectos de biografias de outras pessoas, biografias de línguas familiares ou, em uma extensão variada, aspectos de situações linguísticas de uma determinada comunidade linguística. É esse fato que possibilita a obtenção de informações sobre situações linguísticas analisando (auto)biografias linguísticas (automáticas) ${ }^{4}$ (NEKVAPIL, 2003, p. 64).

Segundo Nekvapil, a biografia linguística também é relevante para estudos sociológicos. Tem uma dimensão obviamente individual, mas também coletiva, ao mesmo tempo em que dá voz a diferentes personagens que compõem o quadro narrativo: pais e mães, professores, governantes.

No que diz respeito ao aprendizado das segundas línguas, a biografia linguística é um dos textos fundamentais que compõem o Portfólio Europeu de Línguas (PEL), proposto pelo Conselho da Europa com o objetivo de fortalecer a cidadania democrática, a proteção da diversidade linguística e cultural e do multilinguismo (CONSEJO DE EUROPA, 2001). Na pesquisa no campo da educação, há trabalhos extensos e diversos em que as narrativas linguísticas dos professores revelam processos de construção da identidade. Hamel, Hecht, Erape Baltazar, Márquez Escamilla (2018) exibem uma experiência de entrevistas autobiográficas com professoras e professores p'urhepechas, membros do projeto escolar “T'arhexperakua-Creciendo Juntos”" de Michoacán, México. Nesta pesquisa, as autobiografias dos professores contrastavam os tempos e formas em que aprendiam a outra língua na infância e como seu bilinguismo e autorreconhecimento étnico se desenvolveram:

\footnotetext{
3 "Besides the speaker's subjective theories on language acquisition and proper language use in different social and communicative circumstances, the language- biographic approach takes interest in individual and collective language related identity constructions as well"

4"By a language biography I understand a biographical account in which the narrator makes a language, or languages - and their acquisition and use in particular - the topic of his or her narrative (cf. FRANCESCHINI, 2001a; 2001b). However, a language is not merely a private matter: the individual learns it from someone and uses it with someone (inside and outside the family), and this is why language autobiographies naturally include aspects of other persons' biographies, family language biographies or, to a varying extent, aspects of language situations of a particular language community. It is this fact that makes it possible to obtain information about language situations by analyzing language (auto)biographies"
} 
"O estudo proporciona valiosa introspecção na motivação etnolinguística profissional e na conscientização de uma equipe de professores que compartilham um projeto escolar reconhecido nacional e internacionalmente" 5 (2018 , p. 90). Vega Ramírez (2018) desenvolve a biografia de um professor do sul do Chile: "A narrativa permite viajar da instabilidade pedagógica do período final do Regime Militar vivido no Chile entre 1973 e 1989 até a instabilidade na consideração da figura do professor, típica do sentimento dos professores em torno das últimas regulamentações do trabalho do professor, especialmente no que diz respeito à Carreira docente" 6 (2018, p. 186).

Relatos autobiográficos contribuem para o estudo de atitudes linguísticas. Vale ressaltar o trabalho de Bataller Catalá (2019) em que desenvolve uma pesquisa sobre atitudes em relação ao espanhol e valenciano utilizando biografias linguísticas: "Este trabalho foca na descrição de algumas representações manifestadas por estudantes valencianos do ensino, em biografias linguísticas, em relação ao multilinguismo, à transmissão de línguas e à construção da identidade através delas"7 (BATALLER CATALA , 2019, p. 16). A pesquisa foi realizada com professores treinados que foram-lhes solicitados a seguinte instrução:

Vocês têm que escrever uma autobiografia linguística onde explicam diferentes aspectos sobre as línguas que conhecem. Você podem dar-lhe o título que quiserem. A extensão tem que ser sobre um folha e você têm que escrevê-lo na forma de história pessoal explicando questões como: Quantas línguas você conhece? Quando você as aprendeu? Como você as aprendeu? Que línguas você ouve falar mais frequentemente? Onde você as ouve? Quais você usa e em que momento? Você conhece falantes de outras línguas? Como você se comunica com eles? Quais são mais fáceis e quais são mais difíceis? Por quê? Você acha interessante aprender línguas? O que você estaria mais interessado em aprender? Por quê? Como você acha que pode aprender melhor uma língua? (BATALLER CATALÁ, 2019, p. 20).

Bataller Catalá discute como são tratadas as noções relativas aos conceitos de "competência linguística", "'falante de castelhano", bem como os significados dados à "língua materna", "primeira língua", segunda língua e "língua estrangeira". O estudo conclui que as biografias linguísticas são uma ferramenta de pesquisa que permite conhecer as crenças dos professores e propor uma formação diferente, a partir de uma didática do multilinguismo,

5 "El estudio aporta una introspección valiosa en la motivación y conciencia etnolingüística profesional de un equipo de docentes que comparten un proyecto escolar reconocido nacional e internacionalmente"

6 "La narración permite transitar desde la inestabilidad docente propia del período final del Régimen Militar vivido en Chile entre 1973 y 1989 hasta la inestabilidad sobre la consideración a la imagen del docente, propia del sentimiento de los profesores en torno a las últimas regulaciones del trabajo del profesor, especialmente lo referido a la Carrera Docente"

7 "El presente trabajo se centra en la descripción de algunas representaciones que manifiestan estudiantes valencianos de magisterio, en biografías lingüísticas, en relación al plurilingüismo, la transmisión de lenguas y la construcción de la identidad a través de aquellas" 
com situações dinâmicas de ensino-aprendizagem que levam ao desenvolvimento de habilidades multilíngues e sociais transformadoras.

Não são poucas as pesquisas que tanto na perspectiva das ciências sociais quanto da sociolinguística e da linguística de contato utilizam a autobiografia linguística como instrumento de análise da realidade social educacional, das convivências linguísticas no mesmo território, dos contextos de migração e deslocamento, bem como de um instrumento no qual conhecemos a voz que fala, o sujeito que se olha no espelho de significados linguísticos.

\section{Metodologia}

Para o desenvolvimento do projeto temos a participação de uma professora de espanhol como língua estrangeira. Ela é uma mulher de 56 anos, originária da Venezuela, com estudos universitários e nível socioeconômico médio-alto. Ela completou duas graduações, uma humanista, a carreira de Letras, e outra de natureza sociológica. Uma vez que nossa colaboradora conhecia os objetivos gerais da pesquisa, só se falou sobre sua biografia linguística no momento em que a coleta de dados começou. Ela fala quatro línguas com diferentes níveis de competência, espanhol, inglês, hebraico e francês. Desde 2011 vive como migrante e esteve em dois países ${ }^{8}$.

Combinamos a técnica da entrevista sociolinguística (cf. MORENO FERNANDEZ, 2012) com a entrevista da biografia linguística (PUJADAS, 1992). Na primeira etapa, foi convidada a escrever sobre sua carreira linguística, especificamente sobre as línguas que falava, como e quando as aprendeu, o que se lembrava de lugares e pessoas em sua vida relacionadas à língua. Para esta fase levamos o repertório de perguntas que Bataller Catalá aplicou aos seus participantes. Em uma segunda etapa do projeto, completou-se a história escrita com uma entrevista aberta que nos permitiu dialogar com a participante para mergulhar em experiências linguísticas. Seguimos Bolivar e Porta (2010) e Wolf-Farré (2018) para que não estruturemos a entrevista:

A ideia da entrevista narrativa é manter o discurso aberto, tanto para o que o entrevistado queira contar, quanto para os possíveis resultados. Ao aplicar o método para fins linguísticos - criando, em todos os sentidos da palavra, um método sociolinguístico - ainda é um método sociológico que se interessa

${ }^{8}$ Vamos nos referir à participante como Tina. 
pela vida da pessoa estudada no geral, mas com foco no papel das línguas (e/ou variedades) do indivíduo [... ${ }^{9}$ (WOLF-FARRÉ, 2018:49).

Finalmente, pedimos a nossa participante que desenhasse sua silhueta e indicasse sobre ela onde no corpo estavam as línguas que fala e as que ela nos havia contado no seu relato. No nosso caso, foi muito relevante passar o participante, quase quadrilíngue, do registro oral-escrito para a dimensão espacial e conhecer a autorrepresentação visual de sua identidade linguística e competência que acompanhou sua autobiografia (cf. BUSCH et al., 2012).

A transcrição da entrevista foi feita adaptando-se de forma muito simplificada o sistema de rotulagem de transcrição proposto pelo PRESEEA, Projeto para o estudo sociolinguístico do espanhol na Espanha e na América, projeto sociolinguístico no qual o corpus foi coletado de diferentes comunidades de língua espanhola (MORENO FERNANDEZ, 2005) e cuja transcrição seguiu diretrizes metodológicas comuns a fim de garantir a comparabilidade dos materiais. As pausas são representadas por um [/] e em parênteses quadrados foram apontados risos e hesitação.

Para a discussão que apresentamos na seção a seguir, seguimos o modo geral de análise de Nekvapil (2003): comentamos trechos da narrativa - tanto trechos do texto autobiográfico quanto da entrevista - relacionados a: a) aprender a língua materna; b) atitudes em relação às línguas faladas; c) avaliações afetivas em relação às línguas; e) ensino de segundas línguas. Em consonância com a abordagem qualitativa, esses tópicos não foram estabelecidos a priori, mas emergiram do relato do participante. É claro que esperávamos que esses tópicos aparecessem, mas não foi através do esquema de perguntas e respostas entre os participantes da entrevista. A seguir, a análise dos textos orais e escritos autobiográficos do entrevistado.

\section{Análise}

Nosso participante começa sua autobiografia com as seguintes palavras:

(5) minha língua materna é espanhola/ meu pai era francês/ nasceu na França de família polonesal minha família mãe é da Romênial na minha infâncial minha avó materna morreu aos 102 anos/ e falava iídichel minha mãe fala inglês/ espanhol e entende iídiche, mas fala muito pouco/.

${ }^{9}$ La idea de la entrevista narrativa es la de mantener el discurso abierto, tanto a lo que el entrevistado quiera contar, como a los resultados posibles. Al aplicar el método con fines lingüísticos - creando, en todo el sentido de la palabra, un método sociolingüístico - todavía se trata de un método sociológico que se interesa por la vida de la persona estudiada en general, pero con un enfoque en el rol de las lenguas (y/o variedades) del individuo. 
No início, ela nomeou o espanhol como língua materna e depois se lembra de todas as línguas faladas pelos pais e avós no contexto familiar da infância. De ascendência judaica, Tina descreve o ambiente linguístico multilíngue familiar em que ela nasce e cresce:

(6) meu pai e minha avó emigraram para a Venezuela após a Segunda Guerra Mundial/ foram da França para a Venezuela / digamos antissemitismo/ e meu pai vem para a Venezuela e imediatamente vem para os Estados Unidos para estudar o ensino médio e a universidade e depois retorna à Venezuela para trabalhar como geólogol para conhecer minha avó e casar com minha mãel após a Segunda Guerra Mundial / estudou lá o médio e a Universidade / retorna a Venezuela / onde sua mãe estava e começa a trabalhar na indústria do petróleo/

(7) então na minha casa eu ouvi iídiche / ouvi inglês / que eu entendia o básico e estava imerso em espanhol / desde jovem eu tenho um amor por gramática e literatura / eu cresci ouvindo meus pais falarem inglês / foram breves conversas e minha mãe falou muito comigo para dar instruções/ como "arrumar a cama" / "lavar os pratos" / "limpar a mesa" / "recolher as coisas da mesa" / algumas instruções que eram todos os dias/ como uma disciplina extrema // e que estava em inglês / então / quando eu estava estudando / Eu não queria estudar inglês na escola / Eu não achava nada importante e talvez fosse por causa dessas repreensões em inglês / instruções de inglês da minha mãe / e / bem / então eu passei pela escola / na universidade eu não estudei inglês/

Em (7) os sentimentos em relação às línguas do ambiente familiar já são notados. Com relação ao inglês, a terceira língua que aprenderá em sua vida, a entrevistada não expressa afeto, e ao nomear o espanhol, fala de língua materna, por ser a primeira que aprendeu no ambiente familiar e pela qual sente amor:

(8) Como eu disse... a primeira língua que eu falei foi espanhol/entre meus pais em inglês para nos dar instruções e nos repreender em inglês/minha avó materna falava com minha mãe iídichel que é a língua judaica que eles falavam na Europa / que é uma mistura de hebraico/polonês/mmm/ Inglês e está escrito como hebraico/isso é o que eu recentemente aprendi recentemente /

(9) Cresci ouvindo quatro línguas/o espanhol era falado em casa/O inglês era falado pelos meus pais um com o outro/ e minha mãe falava conosco em inglês para nos dar instruções e às vezes meu pai também/ porque isso o provocaval meu pai falava com a mãe dele em francês/ e ouvia o iídiche que minha mãe e minha avó materna falavam sobre issol

(10) e eu acho que é por isso que torna mais fácil para mim aprender uma língua de ouvido/ do que lendo ou escrevendo/ 
Achamos a reflexão da nossa participante sobre como aprende línguas relevante. Voltaremos a esta declaração na última parte da entrevista para relacionar sua autobiografia ao ensino. A alfabetização escolar ocorre em uma escola judaica em Caracas. Este trecho da autobiografia mostra os sentimentos que emergem em relação ao hebraico, as contradições entre seus sentimentos e o valor de identidade que a língua tem para a comunidade judaica:

(11) na escola me ensinaram hebraico por onze anos/ mas minha rejeição ao hebraico foi total/ porque eu disse "qual é o ponto de falar uma língua falada apenas em um país? Isso é ridículo! Perder tantas horas da minha vida aprendendo hebraico!" eu não aprendi nada absolutamente nada! Eu acho que a única coisa que me restou/ porque o alfabeto é bonito e o movimento da mão III ou sejal era muito legal mexer a mão e fazer essas letras tão estranhas / que eu gostei e aprendi isso muito bem/ mas eu não sabia sequer sabia o som das letras /II

\section{Percepções crenças sobre o hebraico em Israel}

Nos seguintes segmentos da autobiografia, Tina conta sua primeira viagem de imigração e seu encontro com a língua hebraica:

(12) Eu vou para Israel por causa da situação na Venezuela e emigro porque como judia era o lugar mais fácil que eu poderia chegar rapidamente e obter cidadania /permissão para trabalho/ pela facilidade com que eu poderia conseguir fazer uma vida lál

(13) Aprendi hebraico quando fui para Israel / estudei cinco meses em um [...] / isso é obrigatório para todos os imigrantes / ou seja/ o governo fornece para todas as pessoas que vêm para Israel / como emigrantes / a primeira coisa que eles têm que fazer cinco meses estudar inglês e hebraico / realmente que o aprendizado foi muito difícil entre outros coisas porque éramos quase 40 alunos na sala e isso complicava as coisas / Eu não gostava da língua de jeito nenhum / foi uma coisa que eu rejeitava fortementel embora eu estivesse realmente aprendendo muito bem / minha prova oral foi muito boa para mim / do primeiro nível / que eu não podia acreditar! Eu realmente não gostava da língual foi como um golpe / Eu a sentia como uma língua muito agressiva e eu não entendia por quêl

Em (13) vale destacar como o hebraico é descrito: "uma língua agressiva"; nossa participante valoriza seu aprendizado como difícil, embora ele tivesse boa produção de língua oral. Nesses segmentos da história, a entrevistada volta seu olhar para o contexto coletivo e cultural: 
(14) para entender um pouco a filosofia ou/ as idiossincrasias de Israel/ porque eu não posso dizer sobre os judeus / porque Israel tem cerca de 8 milhões de habitantes / dos quais 2 milhões / Eu acho que são árabes /palestinos e algo como dois ou três milhões de russos / então o que é menos há aí são pessoas que realmente nasceram/cresceram em Israel / em Israel dizem que com a chegada del ou sejal com a proximidade com os palestinos/ bem/ muitas palavras foram criadas que não existiam em hebraico/ por exemplo/ uma saudação normal que antes era shalom / significando paz/ hoje em dia se diz / com a maneira de dizer olá em árabe e muitas outras expressões que se pode dizer "hey/ que divertida é esta expressão / porque é mais fresca"I

A participante reitera sua relação com o hebraico marcada pelo desgosto e convivência em Israel. Os seguintes trechos do relato confirmam a relação língua-pátria que Tina questiona ao declarar sua distância do hebraico:

(15) para entender também a idiossincrasia eu sempre tento entendê-la através da literatura e li um livro muito bom que é a biografia de Amos $\mathrm{Oz} /{ }^{10} \mathrm{Eu}$ entendi muitas coisas sobre idiossincrasias junto com o que aprendi com o livro e como o Estado de Israel foi criado e como foi difícil/ e a importância que teve trabalhar a terra / era um estado totalmente agrícola e sim há muitíssimas palavras de frutas / todas em hebraico / legumes também / os israelenses gritam muito / isso é algo que perfurava meus ouvidos / e esses gritos me pareciam como que não havia intimidade lou sejal que é como se tudo estivesse sendo ventilado/

(16) bem/ essa foi a minha experiência com hebraico / Aprendi muito pouco e quando comecei a trabalhar em Recursos Humanos o que eu fiz foi aprender as palavras-chave que "lista"I "candidatos"I "candidatas"/ "como atender ao telefone"/ "como dar boas-vindas às pessoas quando elas vinham"/ então quando eu os recebia eu iria bater neles porque eu era como "muito suave"/ sempre houve um choque cultural muito grande e eu tive um monte de dificuldade para me adaptar/ na verdade / Eu não conseguia me adaptar nem aprender a língual

(17) quando eu vi que eu não ia aprender a língua / que eu não gostava e não queria / sete ou oito meses depois de estar em Israel eu sabia que não era o meu lugar / Israel não era minha terra natal / Hebraico não era meu língua / que era um mito "e sim / você vai aprender hebraico porque essa é a língua que os judeus falam / eles sempre falaram e está em sua alma" / obviamente para mim não foi assim./

\footnotetext{
${ }^{10} \mathrm{~A}$ participante refere-se ao livro Una historia de amor y oscuridad especificamente o seguinte trecho: [...] Os livros encheram toda a casa: meu pai sabia ler em dezesseis ou dezessete línguas e falar em onze (todos com sotaque russo). Minha mãe falava quatro ou cinco línguas e lia em sete ou oito. Entre eles eles conversaram em russo e polonês quando queriam que eu não os entendesse [...] Pela cultura eles leram principalmente em alemão e inglês, e, claro, à noite eles sonhavam com iídiche. Mas me ensinaram apenas e exclusivamente hebraico: talvez eles temiam que se eu aprendesse outras línguas eu também estaria exposto à sedução da esplêndida e mortal.
}

Europa.OZ, Amos. Una historia de amor y oscuridad. España: Ediciones Siruela, 2007. 
(18) eles só têm 3 tempos verbais/presentes/futuros e passados e são extremamente concretos porque hebraicol para colocá-lo de alguma formal é uma língua artificial/ originalmente por muitos anos era uma língua / digamos a língua sagrada / a língua que só foi usada para orar e a partir dai a língua que eles chamam de rua / a língua falada na rua / então há muitas diferenças que eu relaciono com o espanhol que é muito rico e tem um monte de maneiras de dizer / pedir / solicitar / que em hebraico não existe e eu também acho que eles são muito rudes por causa dessa limitação da língual

Entre os segmentos (15) a (18) descobrimos que a entrevistada questiona um senso de pertencimento para a língua e propõe que adaptar e falar a língua são inseparáveis: "Foi como um golpe / Eu senti como uma língua muito agressiva [...] Os israelenses gritam muito/isso é algo que perfurava meus ouvidos/ e esses gritos me pareciam como que não havia intimidade/ou seja/ como se tudo estivesse sendo ventilado." O participante vai comentar novamente sobre essas descobertas mais adiante. Em nossa opinião, não há ethos linguístico; embora o hebraico represente a língua da alma da comunidade, o que não é compartilhado não tem a ver com estruturas gramaticais ou o léxico, mas com o senso mais amplo de comunidade da fala. O vácuo comunicativo que causa a língua em nosso participante vem da ausência de ethos linguístico - práticas comunicativas representadas em práticas linguísticas comuns a uma comunidade (GARCIA PAREJO; AMBADIANG, 2018) ${ }^{11}$. No fragmento (18), pode-se notar que o hebraico tem, segundo a participante, uma característica estrutura gramatical que o torna uma língua de pouco léxico.

\section{Percepções e crenças sobre o inglês}

A participante continua sua autobiografia com a segunda língua que ela fala: inglês. Aprende inglês antes de viajar para Israel quando ainda mora na Venezuela e é a língua do seu segundo período de imigração.

(19) Aprendi inglês enquanto trabalhava na indústria petrolíferal trabalhando desde 1996/ ali eu estava imbuída em um ambiente onde o inglês era falado/o que se tornou mais fácil foi traduzir do inglês para o espanhol ehhh o escutar/ a leitura/a tradução... escrever não era algo fácill em nada / porque o inglês é uma língua fonética / alias não / não é uma língua fonética / é lido não como está escrito / então / toda vez que eu quero aprender a dizer uma palavra faço isso / Eu faço isso pesquisando no

${ }^{11}$ Tomo o ponto de vista que Garcia Parejo e Ambadiang (2018) desenvolvem em seu trabalho de autorrepresentação, como alunos e falantes espanhóis, de grupos do continente africano e da Europa Oriental; para García-Parejo e Ambadiang, o conceito de ethos linguístico permite "captar a dimensão variável, porém coletiva, dos modos de comportamento de um grupo, bem como a agentividade dos falantes individuais" 
dicionário como se pronuncia / se eu nunca a escutei e muitas vezes o que acontece comigo é que quando leio uma palavra e digo "mas/ o que é isso?" ou uma pessoa entende no contexto/ mas quando eu procuro no dicionário eu percebo que é uma palavra que eu usei toda a minha vida, mas eu não sabia como se escrevia...

(20) E: Por que você aprendeu inglês?

Tina: é fundamental fala inglês/era por um motivo prático/Eu nunca quis estudá-lo antes / além disso estava procurando opções fora da Venezuela /

A participante atualmente vive em Nova York e está, pela primeira vez, em um ambiente totalmente anglófono:

(21) ehhh das línguas que ouço atualmente mais frequentemente vivendo nos Estados Unidos é inglês/ e eu ouço espanhol/ às vezes / não é algo diário / Inglês é uma língua muito prática / é muito direta / mas as pessoas fazem tudo de uma forma ... "por favor/você poderia ser tão gentil/ could you please/ would you/ may you" e sempre / por exemplo/ nas aulas dizem would you like to read? e você sabe que você tem que ler/ mas eles não dizem "você lê" "leia V" / não / eles sempre perguntam se você quer ler / claro / você não tem escolha! mas/é o caminho/

(22) Moro aqui em Nova York há 3 anos / Ainda estou aprendendo/ assim como estou aprendendo espanhol/ Acho que as línguas são aprendidas o tempo todo e o inglês trato sempre de...bom/ Eu não sei se eu trato ou que por acaso meus amigos e meus vizinhos as pessoas com quem eu falo na rua / comumente / eu diria que em 95\% eles falam inglês / então isso é muito bom porque com que eles falam / ehhh / ah/ também como eles escrevem os textos / que é muito comum / todas as contrações que

(23) fazem/

\section{Sobre o espanhol nos Estados Unidos}

Também surgem reflexões sobre preconceito e discriminação nos Estados Unidos: acreditar que alguém fala espanhol pode ser discriminatório.

(24) $O$ inglês eu ouço isso diariamentel o tempo todo/ para todos os lugares aonde eu vou/ na rual na bibliotecal na livrarial no supermercado/ às vezes na Netflix / Eu uso para me comunicar com os americanos inglês/ $e$ quando eu vejo que uma pessoa fala espanhol ou eu acho que eles falam espanhol / ehh / que talvez isso possa ser aqui como uma discriminação / dizer algo em espanhol para alguém que vê o rosto do mexicano / porque muitos se sentem ofendidos / Então eu vou sentindo o terreno para ver quando eu posso falar espanhol/ mas sempre são coisas muito básicas / também no metrô às vezes "señora/ siéntese acá" "'ayy/ mija/ la felicito'/ você fala muito bem espanhol / onde você aprendeu" e assim eu falo às vezes com senhorinhas / eles são muito fofas/ e claro / você também vê a questão de discriminação / que é / um branco não pode falar "tão bem" o espanhol/ 
Perguntamos à participante por que a senhora do metrô diz "La felicito/ você fala muito bem espanhol". Para Tina, esta senhora a parabeniza porque ela a confunde com uma americana nativa, "certamente por causa da minha cor de pele/ e talvez das roupas".

Nos segmentos (24) e (25), o entrevistado ressalta a importância do conhecimento sociopragmático para falar uma língua:

(25) E então... coisas que sim/ você percebe com a cultura / como você deve abordar as pessoas / como falar com elas / ou seja/ há todo um tópico de comunicação não verbal que é sempre importantel aqui você não pode ficar fazendo contato visual que se no metrô ou ver uma criancinha e sorrir para ela / as pessoas encaram isso mal / Eu acho que já me adaptei a isso / no início eu não consegui, mas eu consegui muito bem/

(26) E: O que significa para você então falar várias línguas?

Tina: falar outras língua pra mim é maravilhoso / porque você encontra uma amplitude / Eu sinto que a mente vai se abrindo para mim / Eu sinto que vou começando a conhecer outras culturas / outras maneiras de dizer coisas / também para escrevê-las/

E: Mas você não se sentia assim sobre hebraico...

Tina: não/ porque eu sentia o hebraico como artificial/ com o inglês também acontece comigo que muitas vezes são mais os modais/ comunicação / do que a língua

\section{Como docente $\mathbf{L E} \mathbf{E}^{12}$}

(27) Eu dei aulas de inglês e espanhol em Israel e a experiência eu diria foi muito estranha porquel um / era um intercâmbio com um israelense e o que mais me custava eram coisas culturais e a / como se diz / pode ser os modais / Eu não sei dizer / como você pode chamar isso / "obrigado"I "por favor"/ "poderia"I "poderia"/ eles só têm 3 tempos verbais/presentes/futuro/ e passado e são extremamente concretos porque o hebraico/ para colocá-lo de alguma forma / é uma língua artificial / originalmente por muitos anos era uma língua / digamos a língua sagrada / a língua que só era usada para orar e a partir daí a língua que eles chamam / a língua de rua / a língua que foi falada na rua / então há muitas diferenças que eu concebo com o espanhol que é muito rico e tem um monte de maneiras de dizer / de pedir / solicitar / que em hebraico não existe e eu acredito que eles são muito rude por causa dessa limitação da língual

(28) Também lhes dei aulas de espanhol aquil o que mais custa aos americanos é a pronúncia e todas as complicações que os tempos verbais trazem em espanhol / e bom / que são extremamente concretos e em espanhol há muitas maneiras de dizer coisas / Eu sino o inglês mais pragmático / mais para os negócios / mais orientado para algo orientado como muito eficiente e muito politicamente correto / o que eles chamam de to be politel

${ }^{12}$ A participante fez cursos de curta duração para professores da ELE e trabalhou como professora de ELE 
(29) em Israel a atitude em relação ao espanhol sempre foi de... "De onde você é? Venezuela? Ah / Venezuela / que gostoso! / como o espanhol é lindo!" /sempre com muita curiosidade e eu diria fascínio porque o espanhol é realmente bonito/nos Estados Unidos eu não posso nem perguntar às pessoas que eu acho que falam espanholle é a minha lingua materna/minha cultural

Nesses trechos, a participante relaciona novamente o ensino de línguas ao desenvolvimento da competência sociopragmática e linguística.

(30) E: Você de alguma forma traz sua própria experiência linguística para a sala de aulalé uma maneira de dizer se você se conecta com os sentimentos e classificações dos alunos? você diz a eles sobre os padrões comunicativos que têm que aprender?/

Tina: nunca me ocorreu/Eu sempre acho que é uma questão pessoal/que as pessoas decidem estudar uma língual Eu não saberia como fazer isso, mas agora eu vejo que é muito importantelem Israel/muitas vezes em sala de aula/ Foi mais eu pensei que o que eu ouvi dos professores / quando o que você quer é trabalhar para sobreviver ou ganhar um salário você realmente não quer "aprender" / você quer falar e basta/como outra atitude/Vivi isso hebraico/não com o inglês/antes era toda a felicidade de aprender agora eu vejo a angústia esta é a preocupação das pessoas que precisam falar outra língua / Eu leio muita literatura e mídia impressa e televisão para aprender as formas de falar /que eu não tinha visto em nenhum curso de inglês / e porque eu quero falar melhor inglês para ter um bom trabalho/

Tina: Eu não pensei que antes/ mas agora eu vejo isso/ a partir da minha própria experiência.

(31) E: Que tipo de alunos você teve?

Tina: ensinar espanhol a povos nativos nos Estados Unidos não é fácil/porque muitos querem que o professor seja totalmente bilíngue e criticá-lo se ele não él "como ele vai ensinar outra língua para nós se ele não fala inglês?" e para ensinar a Comunidade de Mexicanos/Comunidade, por exemplo, para o crianças de quem veiolentão você precisa de muita sensibilidade/com alguns você tem que ser como um técnico/profissional /e em Israel eu dei as explicações/quase semprelem inglês /quando você vai para uma academia é uma coisa /quando você está na faculdade outra coisa muito diferentel

(32) E: Você disse que aprende mais fácil de ouvido/ do que lendo ou escrevendo/você levou esse conhecimento pessoal/subjetivo/ para a sala de aula?

Tina: Sim/mas eu percebo agora que você tem que levar isso muito mais em conta / muito mais

Após a entrevista, passamos para a fase final do estudo. Para seu retrato linguístico, pedimos a Tina para desenhar seu corpo e colocar as três línguas que ela fala nessa silhueta. A Figura 1 mostra onde ficam o espanhol, o inglês e o hebraico. 
Figura 1 - Retrato linguístico

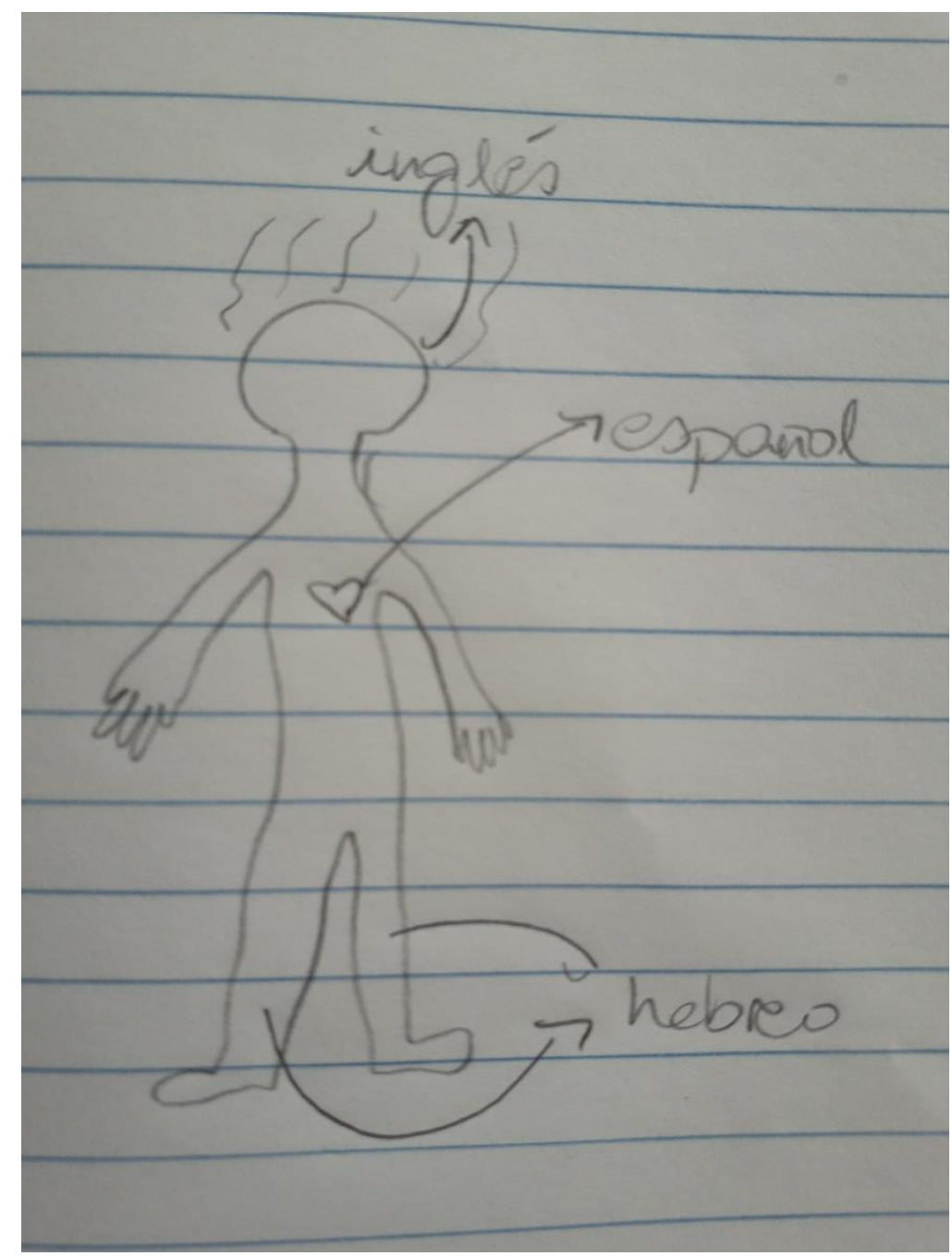

Fonte: elaboração própria

Tina escolheu três partes do corpo humano para localizar cada língua: a cabeça, o coração, as pernas. Quando ela pediu para nos explicar o retrato, ela disse:

(33) no meu coração... O espanhol está no meu coraçãol definitivamentel Inglês na minha cabeça porque é uma língua muito pragmática/tem um monte de palavras para o politicamente correto / Eu não sei como dizer isso / very politel e eu percebo agora que eu estou trabalhando que é impressionante/impressionante / como você tem que escrever e falar / e o hebraico está em minhas pernas / porque quando morei em Israel percebi que estava em uma bomba relógio e o que você tem são as pernas para correr e como judia o estado de Israel representa de alguma forma como nossa sobrevivência/isso é para mim / Eu sempre digo que é para mim porque eu não sei como é para os outros e é por isso que eu o coloco nas pernas / para ser capaz de correr em qualquer circunstância onde eu sinta perigo/ 
O coração simboliza o afetivo-emocional da identidade autorrepresentada; as pernas aparecem representando o movimento físico que simboliza a caminhada e a salvação na diáspora; e a cabeça é escolhida para simbolizar o racional-pragmático. Não é um corpo dividido em três partes com três línguas, é o corpo com a intersecção de três ethos linguísticos: práticas comunicativas, funcionalidade, sentimentos.

(34) assim são as línguas em mim/mas como a alma e o corpo são os mesmos /

(35) E: você é mais uma língua do que outra? Há alguma parte do seu corpo que você marcou que é mais importante para você?

Tina: nenhuma/a três/as três línguas/ e a cabeça/pernas/e coração/agora que eu digo que me vejo mais/Eu não sei/estendido/múltiplo /

Embora as condições de vida do nosso participante não sejam de vulnerabilidade social ou segregação por causa de sua origem, o sentimento de perda da língua materna está presente:

(34)E: espanhol é a língua que eu mais gosto e talvez eu tenha no meu coração como um desejo de que eu não estou mais em um país onde o espanhol é falado e é algo que eu preciso muito porque eu sinto que o meu espanhol está empobrecendo/tanto falado como escritol

A língua perdida permanece como expressão da identidade familiar-cultural. Ele é o espanhol que carrega preconceitos e segregações, o espanhol que não se escuta mais e com o qual o ethos linguístico é mais compartilhado, o desejo de contar, o desejo de compartilhar experiência, de fazer contato com o outro.

\section{Considerações finais}

Nesta pesquisa, o método biográfico-narrativo tem sido aplicado para o estudo de avaliações, representações, crenças e atitudes e para conhecer seu objetivo como estratégia de reflexão docente. Combinaram-se autobiografia linguística, entrevista e retrato linguístico Trabalhamos com a autobiografia de uma mulher multilíngue e professora de espanhol como língua estrangeira. A história nos permitiu conhecer sua trajetória linguística, suas percepções sobre as línguas que fala e como cada uma dessas línguas constitui seu passado simbólicoemocional. É revelada em suas palavras, a noção de identidade linguística, no seu caso como uma intersecção de três línguas por sua vez com três saberes culturais compartilhados em diferentes graus, assumidas como padrões comunicativos e também como pilares afetivos. $\mathrm{O}$ relato de Tina mostrou como, a partir do eu biográfico, pode-se reconhecer crenças e atitudes que permitem ao professor se posicionar como aprendiz de línguas, aquele aprendiz 
complexo, diglósico, múltiplo, deslocado migrado, que ocupa a sala de aula com um corpo e uma alma. Seu próprio caminho autobiográfico levou a novas reflexões sobre sua ação de ensino.

\section{REFERÊNCIAS}

BATALLER CATALÁ, A. Del concepto de lengua materna al de competencia plurilingüe. Representaciones de la identidad y la enseñanza multilingües a partir de biografías lingüísticas. Onomázein, n. 44, p. 15-36. 2019. Disponible em:

http://onomazein.letras.uc.cl/04_NumeroDescarga/n44/Descarga44_2.html. Acceso el: jan. 2020.

BOLÍVAR, A.; PORTA, L. La investigación biográfico narrativa en educación: entrevista Antonio Bolívar. Revista de Educación [en línea], 2010.

CONSEJO DE EUROPA. Marco común europeo de referencia para las lenguas: aprendizaje, enseñanza, evaluación. Strasbourg: Council of Europe, 2001. Disponible en: http://cvc.cervantes.es/obref/marco/. Acceso el: jan. 2020.

GARCÍA PAREJO, I.; AMBADIANG, T. La enseñanza de lenguas no maternas en la era de las migraciones: la importancia de las biografías linguiísticas. Doblele. Español lengua extranjera. Revista de Lengua y Literatura, n. 4, p. 22-40, dez. 2018.

HAMEL, R. E.; HECHT, A. C.; ERAPE BALTAZAR, A. E.; MÁRQUEZ ESCAMILLA, H. B. Uandakurhintskua- biografías lingüísticas de docentes p'urhepechas. De la escolaridad traumática a la creación de un modelo educativo alternativo. Revista de Investigación Educativa, n. 27, jul./dez. 2018.

MOLINIÉ, M. Biographie langagière et apprentissage plurilingue. Le Français dans le monde:recherches et applications, n. 39, 2006. Disponible em: https://halshs.archivesouvertes.fr/halshs-01224908/. Acceso el: jan. 2020.

MORENO FERNÁNDEZ, F. Sociolingüística cognitiva: proposiciones, escolios y debates. Madrid: Iberoamericana, 2012.

MORENO FERNÁNDEZ, F. Corpus para el estudio del español en su variación geográfica y social: el corpus PRESEEA. Oralia, n. 8, p. 123-140, 2005.

NEKVAPIL, J. Language biographies and the analysis of language situations: on the life of the German community in the Czech Republic. International Journal of the Sociology of Language, n. 162, p. 63-83, 2003.

NOVACK, K. What can language biographies reveal about multilingualism in the Habsburg Monarchy? A case study on the members of the Illyrian movement. Jezikoslovlje, v. 13, n. 2, p. 395-417, 2012.

PUJADAS, J. J. El método biográfico. El uso de las historias de vida en ciencias sociales. Madrid: Centro de Investigaciones Sociológicas, 1992. 
VEGA RAMÍREZ, J. F. A. Yo no quería ser profesora. Un ejemplo práctico del método biográfico-narrativo. Teoría de la Educación. Revista Interuniversitaria, v. 30, n. 2, p. 177-199, 2018.

WOLF-FARRÉ, P. El concepto de la Biografía Lingüística y su aplicación como herramienta lingüística. Lengua y Habla, n. 22, p. 45-54, 2018.

\section{Como se referir a este artigo}

MALAVER, Irania. Autobiografia linguística. Atitudes, crenças e reflexões para o ensino de línguas. Rev. EntreLínguas, Araraquara, v. 6, n. 1, p. 176-193, jan./jun., 2020. e-ISSN: 2447-3529. DOI: https://doi.org/10.29051/el.v6i1.13664

Submetido em: 30/07/2019

Revisões requeridas em: 30/08/2019

Aprovado em: 30/11/2019

Publicado em: 06/01/2020 